\title{
EFEITO INSULINOTRÓPICO E CITOPROTETOR DO EXTRATO BRUTO DE FOLHAS DE EUGENIA UNIFLORA L.
}

Simoní Marinéia Braatz ${ }^{1}$, Elise Tatiane Felipe ${ }^{1}$, Carla Cristine Kanunfre ${ }^{2}$, Dionízia Xavier Scomparin ${ }^{2}$, Henriette Rosa de Oliveira Emilio²

Universidade Estadual de Ponta Grossa - UEPG, Departamento de Biologia Geral, Ponta Grossa, PR. E-mail: henry.emilio@gmail.com

\section{RESUMO}

Folhas de Eugenia uniflora L. ("pitangueira") são popularmente utilizadas como uma alternativa para o tratamento do diabetes mellitus. O objetivo deste trabalho foi avaliar a citotoxidade, a atividade antioxidante, citoprotetora e insulinotrópica dos extratos brutos de folhas de Eugenia uniflora L. sobre a linhagem tumoral de células beta secretoras de insulina (RINm5f). A atividade antioxidante foi analisada pelo método de FolinCiocalteau, a citotoxidade e a citoproteção pelos métodos de redução do MTT (brometo de 3-(4,5-dimetil-2tiazolil)-2,5-difenil-2H-tetrazólio), coloração por HE (hemtoxilina-eosina) e o efeito insulinotrópico por radioimunoensaio. $O$ extrato alcoólico (ALC) apresentou apenas $8,6 \%$ do conteúdo fenólico obtido para o extrato aquoso (AQ). Ambos apresentaram baixa citotoxicidade e o ALC apresentou um significativo efeito insulinotrópico. Tanto o AQ quanto o ALC apresentaram efeito citoprotetor, aumentando a viabilidade celular e prevenindo as alterações na morfologia celular induzidas pelo peróxido de hidrogênio $\left(\mathrm{H}_{2} \mathrm{O}_{2}\right)$. Os resultados obtidos neste trabalho são indicativos do potencial destes extratos no combate ao estresse oxidativo, uma característica frequentemente relacionada ao diabetes mellitus.

Palavras-chave: antioxidantes, citoproteção, citotoxicidade, flavonoides, peróxido de hidrogênio.

\section{INSULINOTROPIC AND CYTOPROTECTIVE EFFECT OF CRUDE LEAF EXTRACT OF Eugenia uniflora L.}

\begin{abstract}
Eugenia uniflora L. leaves ("pitangueira") are popularly used as an alternative to the treatment of diabetes mellitus. The objective of this work was to evaluate the cytotoxicity, antioxidant, cytoprotection and insulinotropic activity of crude leaf extracts of Eugenia uniflora L. on the insulin secreting beta cell line (RINm5f). The antioxidant activity was analyzed by the Folin-Ciocalteau method, cytotoxicity and cytoprotection using MTT reduction method (3-(4,5-dimethyl-2-thiazolyl)-2,5-diphenyl-2H-tetrazolium bromide), HE staining (hematoxylin-eosin) and the insulinotropic effect by radioimmunoassay. The alcoholic extract (ALC) presented only $8.6 \%$ of the phenolic content obtained for the aqueous extract (AQ). Both showed low cytotoxicity and LAC presented a significant insulinotropic effect. Both AQ and ALC showed a cytoprotective effect, increasing cell viability and preventing changes in cellular morphology induced by hydrogen peroxide $\left(\mathrm{H}_{2} \mathrm{O}_{2}\right)$. The results obtained in this work are indicative of the potential of these extracts against oxidative stress, a characteristic frequently related to diabetes mellitus.
\end{abstract}

Keywords: antioxidants, cytotoxicity, cytoprotection, flavonoids, hydrogen peroxide.

\section{INTRODUÇÃO}

O conhecimento empírico sobre plantas medicinais é utilizado por muitas pessoas como o único recurso terapêutico. Grande parte da população mundial, principalmente de países em desenvolvimento, utiliza extratos vegetais de diversas partes de plantas, tais como folhas, raízes, cascas e frutos, como medicamento ${ }^{1}$. Os benefícios atribuídos a esses extratos são muito variados, sendo destinados para o controle, prevenção e tratamento de diversas patologias. No Brasil, diversas plantas são usadas na forma de extratos brutos, infusões ou emplastros no tratamento de infecções, entretanto, a grande 
maioria delas não possui nenhuma comprovação científica de sua eficácia ${ }^{2}$. Apenas uma pequena porcentagem das plantas e extratos vegetais foi adequadamente estudada quanto a sua composição, atividade farmacológica e segurança, não obstante, muitos acabam sendo utilizados e amplamente difundidos nas comunidades sem ser levado em consideração o risco associado à sua toxicidade.

Muitas espécies de plantas têm sido popularmente ou experimentalmente utilizadas para a prevenção e tratamento do diabetes mellitus $^{3-5}$. Essa intensa utilização provocou aumento no número de investigações experimentais e clínicas para validar as propriedades antidiabéticas que têm sido empiricamente atribuídas a essas plantas. 0 principal efeito antidiabético apresentado pela maioria das plantas utilizadas é a atividade hipoglicemiante. Entretanto, há uma grande variedade de substâncias responsáveis e de mecanismos envolvidos na redução dos níveis de glicose. Entre as substâncias com conhecida atividade hipoglicemiante se destacam os terpenoides, alcaloides, carboidratos e flavonoides. Apesar de muitas dessas substâncias apresentarem um real potencial terapêutico, é importante ressaltar que muitas delas podem apresentar um efeito antidiabético secundário a um efeito colateral, como por exemplo, hepatotoxicidade, não sendo, portanto, indicada a sua utilização ${ }^{6}$.

Diversos mecanismos da ação hipoglicemiante e antidiabética já foram descritos, tais como efeitos diretos no pâncreas pela estimulação da secreção de insulina pelas células B pancreáticas (efeito insulinotrópico) ${ }^{7,8}$, efeito insulinomimético ${ }^{9}$, estimulação da metabolização da glicose $^{10}$ e a atividade antioxidante direta ou indireta, através da estimulação de defesas antioxidantes nas células B pancreáticas ${ }^{11,12}$. Efeitos periféricos por estimulação do aumento de defesas antioxidantes nos tecidos periféricos também já foram descritos, além do aumento da sensibilidade dos tecidos periféricos à insulina ou aumento da expressão de receptores da mesma ${ }^{11-13}$.Os antioxidantes naturais contidos em plantas medicinais e dietéticas constituem o grupo de compostos antidiabéticos mais estudado. Esses compostos apresentam a capacidade de prevenir o estresse oxidativo e, consequentemente, $\mathrm{o}$ desenvolvimento $\mathrm{e}$ as complicações de diversas patologias, entre as quais o diabetes mellitus ${ }^{14}$.

O diabetes mellitus consiste em um grupo heterogêneo de distúrbios metabólicos desencadeados pela deficiência na produção pancreática da insulina e/ou resistência periférica a ação desse hormônio. Uma das principais alterações metabólicas no diabetes mellitus é a hiperglicemia. Em vários tecidos, o aumento da oxidação da glicose é acompanhado por elevada geração de espécies reativas de oxigênios (EROs), tais como $\mathrm{H}_{2} \mathrm{O}_{2}$, radicais hidroxil e superóxido, e por um desequilíbrio entre a geração de agentes oxidantes e as defesas antioxidantes celulares ${ }^{15}$. As células produtoras de insulina são particularmente susceptíveis a ação de espécies reativas e seus consequentes danos celulares devido à baixa expressão e atividade das enzimas antioxidantes $^{16,17}$. 0 estresse oxidativo em ilhotas pancreáticas e células secretoras de insulina pode ocorrer devido a uma produção excessiva de espécies reativas mitocondriais, aumento na produção de EROs derivadas da elevada atividade da enzima NAPH oxidase ou ainda por falhas nos mecanismos de defesa antioxidante ${ }^{18,19}$.

As plantas, assim como os animais, possuem sistemas antioxidantes. A atividade antioxidante apresentada por vários vegetais, incluindo frutos, folhas, sementes e raízes, está correlacionada ao seu teor de compostos como cafeína, aminas, alcaloides, ligninas, terpenos oxidados, taninos e fenóis, muitos destes formando um grupo conhecido como compostos fenólicos ${ }^{20,21}$. Dentre 0 grande grupo de compostos fenólicos estão incluídos os flavonoides que englobam ainda as antocianinas, flavonas, flavanonas, isoflavonoides, flavanóis e flavonóis. Os flavonoides mais investigados são a quercetina, a miricetina, a rutina e a naringenina e muitos destes são encontrados em extratos foliares ${ }^{22}$. Eles têm sido amplamente estudados por apresentarem comprovados efeitos na redução do risco ou retardo do desenvolvimento de doenças cardiovasculares, câncer, diabetes e modulação de outros processos biológicos essenciais em mamíferos ${ }^{23}$. Um estudo prospectivo realizado na Finlândia, por exemplo, mostrou que a ingestão de alguns tipos específicos de flavonoides, incluindo quercetina e miricetina, está inversamente associada ao risco de desenvolvimento do diabetes tipo $2^{24}$. Muitos dos efeitos antidiabéticos dos flavonoides são atribuídos a sua capacidade de preservação da 
funcionalidade das células B pancreáticas através da redução de danos induzidos pelo estresse oxidativo $^{25}$

A Eugenia uniflora L. (pitangueira) é uma planta pertencente à família Myrtaceae e seus frutos comestíveis são muito conhecidos e apreciados no Brasil. Vários efeitos terapêuticos têm sido atribuídos às folhas de Eugenia uniflora L., dentre os quais destacam-se a sua ação hipotensora, antigota, antirreumática, digestiva e hipoglicemiante. É uma planta rica em compostos fenólicos com propriedades antioxidantes, sendo os mais abundantes a quercetina e a miricetina e também taninos, como o ácido gálico e o elágico ${ }^{26,27}$. O efeito antidiabético das folhas de Eugenia uniflora L. foi relacionado a atividade inibitória do extrato sobre enzimas intestinais, tais como $\alpha$-glicosidase, maltase e sacarase ${ }^{28}$, resultando na redução da absorção de carboidratos e consequente controle da glicemia. Entretanto não há estudos relacionando a ação direta do extrato de folhas Eugenia uniflora L. sobre o pâncreas endócrino, mais especificamente sobre a funcionalidade das células secretoras de insulina. Sendo assim, o objetivo deste trabalho foi investigar a citotoxidade, a capacidade citoprotetora e insulinotrópica do extrato de folhas de Eugenia uniflora L. sobre células secretoras de insulina.

\section{METODOLOGIA}

Neste estudo foram utilizados reagentes de qualidade analítica. O meio de cultura RPMI 1640, soro fetal bovino, penicilina e estreptomicina foram adquiridos da Vitrocell (Campinas, Brasil); MTT- brometo de 3-(4,5dimetil-2-tiazolil)-2,5-difenil-2H-tetrazólio, da Sigma Chemical (St Louis, MO, USA); a tripsina foi adquirida da GibcoBRL, Life Technologies (Grand Island, USA) e o dimetilsulfóxido (DMSO) da Biotec (Curitiba, Brasil). As células RINm5f (derivadas de insulinoma de rato) foram gentilmente doadas pelo Prof. Rui Curi da Universidade de São Paulo (ICB/USP).

As folhas frescas de Eugenia uniflora L. foram coletadas na forma de um pool de folhas provenientes de diversas árvores do campus da Universidade Estadual de Ponta Grossa (UEPG). A espécie foi devidamente identificada e uma exsicata encontra-se sob o registro 14536 no herbário do Departamento de Biologia Geral (Universidade Estadual de Ponta Grossa - UEPG). Para o extrato aquoso ( $\mathrm{AQ}$ ), as folhas frescas (200g) foram picadas e aquecidas juntamente com $3600 \mathrm{~mL}$ de água destilada a $70-80^{\circ} \mathrm{C}$ por 40 min. $O$ extrato foi filtrado em gaze dupla, liofilizado (rendimento final de aproximadamente $15 \mathrm{~g})$ e dissolvido em água destilada para utilização. Já o extrato alcoólico (ALC) foi obtido através da maceração de folhas frescas $(85 \mathrm{~g}) \mathrm{em}$ $960 \mathrm{~mL}$ de álcool etílico 95\% e armazenado a temperatura ambiente (protegido da luz) por 7 dias. O extrato foi filtrado em gaze dupla e concentrado por rotaevaporação (rendimento final de aproximadamente $70 \mathrm{~mL}$ ).

A concentração de fenóis totais presentes nos extratos de folhas foi determinada pelo método de Folin-Ciocalteau ${ }^{29}$. Este método baseia-se na produção de óxidos azuis de wolfrâmio $\left(\mathrm{W}_{8} \mathrm{O}_{23}\right)$ e molibdênio $\left(\mathrm{M}_{8} \mathrm{O}_{23}\right)$ a partir da oxidação de compostos fenólicos em meio básico. As leituras das absorbâncias foram realizadas a $720 \mathrm{~nm}$ (leitor de microplaca marca Biotek, $\mu$ Quant). Catequina foi usada como padrão para construção de uma curva de calibração (40; 80; 100; 120; 140; 160; 180; 200 $\mu \mathrm{g} / \mathrm{mL}$ de catequina). Os resultados foram expressos em $\mu \mathrm{g} / \mathrm{mL}$ equivalentes de catequina/mg de extrato.

A viabilidade celular foi avaliada pelo método de redução do MTT. Esse método é utilizado como um indicativo da atividade metabólica, através da avaliação da integridade e atividade mitocondrial. $\mathrm{O}$ método baseia-se na capacidade da enzima succinato desidrogenase mitocondrial em reduzir o MTT a cristais de formazan ${ }^{30}$.

As células RINm5f foram cultivadas em meio de cultura RPMI 1640 suplementado com 10\% de FBS (soro fetal bovino), penicilina $(100 \mathrm{U} / \mathrm{mL}$ ) e estreptomicina $(100 \mu \mathrm{g} / \mathrm{mL})$ e mantidas a $37^{\circ} \mathrm{C}$ em atmosfera umidificada contendo $5 \%$ de $\mathrm{CO}_{2}$. As células $\left(5 \times 10^{4} /\right.$ poço) foram cultivadas por $24 \mathrm{~h}$ para adesão em placa de 96 poços (8 replicadas de cada grupo). Posteriormente as células foram incubadas na presença ou ausência de diferentes concentrações do $A Q(150 ; 75 ; 50 ; 25$ e $12,5 \mu \mathrm{g} / \mathrm{mL})$ e alcoólico (500; 250; 125; 62,5 e 31,25 $\mu \mathrm{g} / \mathrm{mL}$ ) por $46 \mathrm{~h} / 37^{\circ} \mathrm{C}$ em meio RPMI 1640 . Após incubação, o sobrenadante foi desprezado e as células foram lavadas com tampão fosfato-salino (PBS). Foram adicionados a cada poço $200 \mu \mathrm{L}$ de solução de MTT em meio de cultura (concentração final $0,5 \mathrm{mg} / \mathrm{mL}$ ) e as células foram incubadas por $1 \mathrm{~h} / 37^{\circ} \mathrm{C}$. O precipitado (formazan) foi extraído com a adição de $200 \mu \mathrm{L}$ de DMSO e a absorbância foi determinada 
em $546 \mathrm{~nm}$ (leitor de microplaca marca Biotek, $\mu$ Quant). A viabilidade celular foi expressa em $\%$ de viabilidade em relação ao controle (controle normalizado para $100 \%$ ).

A capacidade citoprotetora dos extratos foi avaliada pelo método de redução do MTT. As células ( $5 \times 10^{4} /$ poço) foram cultivadas por $24 \mathrm{~h}$ para adesão em placa de 96 poços (8 replicadas de cada grupo). Após adesão, as células foram incubadas na presença ou ausência de $A Q(75 ; 50 ; 25$ e $12,5 \mu \mathrm{g} / \mathrm{mL})$ e alcoólico (250; $125 ; 62,5$ e $31,25 \mu \mathrm{g} / \mathrm{mL}$ ) por 24 horas $/ 37^{\circ} \mathrm{C}$. Após tratamento, o meio de cultura foi removido e as células foram lavadas com PBS. Solução de $\mathrm{H}_{2} \mathrm{O}_{2}(150 \mu \mathrm{M})$ foi adicionada em cada poço e as células foram incubadas por $2 \mathrm{~h} / 37^{\circ} \mathrm{C}$. Após estresse oxidativo induzido pelo $\mathrm{H}_{2} \mathrm{O}_{2}$, as células foram lavadas e incubadas por $1 \mathrm{~h} / 37^{\circ} \mathrm{C}$ na presença de solução de $\mathrm{MTT}$ (concentração final 0,5 $\mathrm{mg} / \mathrm{mL}$ ). O precipitado formazan foi extraído com DMSO e a absorbância foi determinada em $546 \mathrm{~nm}$ (leitor de microplaca marca Biotek, $\mu$ Quant). A viabilidade celular foi expressa em \% de viabilidade em relação ao controle. A capacidade citoprotetora foi determinada através da comparação com o grupo controle $\mathrm{C}_{\mathrm{H} 2 \mathrm{O} 2}$ (ausência de extrato e estresse induzido por $\mathrm{H}_{2} \mathrm{O}_{2}$ ).

A concentração de insulina nas amostras obtidas após secreção estática foi determinada por radioimunoensaio ${ }^{31,32}$. As células foram cultivadas $\left(5 \times 10^{5}\right.$ célula/poço) em placas de 24 poços e incubadas por $22 \mathrm{~h}$ para adesão. Em seguida as células foram lavadas com PBS e foi adicionado $1 \mathrm{~mL}$ da solução de Krebs-Henseleit (KH) contendo $0,2 \%$ de albumina sem glicose por 30 minutos $/ 37^{\circ} \mathrm{C}$ para a estabilização celular. A solução $\mathrm{KH}$ foi desprezada e adicionou-se em cada poço $1 \mathrm{~mL}$ das soluções a serem testadas: 75; $50 ; 25$ e $12,5 \mu \mathrm{g} / \mathrm{mL}$ de $A Q$ e $250 ; 125 ; 62,5$ e $31,25 \mu \mathrm{g} / \mathrm{mL}$ de $\mathrm{ALC}$ em solução $\mathrm{KH}$ contendo $0,2 \%$ de albumina e $5,6 \mathrm{mM}$ de glicose. As placas foram incubadas por $60 \mathrm{~min} / 37^{\circ} \mathrm{C}$ e após incubação, o sobrenadante de cada poço foi suavemente homogeneizado e as amostras coletadas para determinação da concentração de insulina.

Células RINm5f ( $1 \times 10^{5}$ célula/poço) foram cultivadas em placas de 24 poços por $24 \mathrm{~h} / 37^{\circ} \mathrm{C}$ para adesão. As concentrações de extrato que promoveram maior citoproteção no ensaio de viabilidade celular (redução do MTT) foram utilizadas para avaliação do efeito na morfologia celular. Após adesão, as células foram incubadas na ausência ou presença das seguintes concentrações de extrato: 75,50 e $25 \mu \mathrm{g} / \mathrm{mL}$ de AQ e $250 \mu \mathrm{g} / \mathrm{mL}$ de ALC. Após $24 \mathrm{~h}$ de exposição, o meio foi desprezado, as células lavadas com tampão-fosfato PB 0,1 $\mathrm{M}$ e foi adicionado sobre elas uma solução de $\mathrm{H}_{2} \mathrm{O}_{2}$ a $150 \mu \mathrm{M} / 2 \mathrm{~h} / 37^{\circ} \mathrm{C}$. Posteriormente, as células foram novamente lavadas com tampão-fosfato PB $0,1 \mathrm{M}$ e fixadas com paraformaldeído (PFA) $4 \%$ por $15 \mathrm{~min}$. As células foram coradas com hematoxilina-eosina (HE) e a morfologia celular foi analisada em microscópio óptico invertido (Medilux).

A análise estatística dos dados foi realizada utilizando o programa GraphPad Prism 5. Os resultados foram expressos como média \pm erro padrão da média (EPM) e analisados estatisticamente por análise de variância (ANOVA), seguida pelo pós-teste de Tukey, adotando-se como limite mínimo de significância $p<0,05$.

\section{RESULTADOS}

A concentração de fenóis totais $(n=3)$ presentes nos extratos de folhas de pitanga foi de $440,27 \mu \mathrm{g} / \mathrm{mL}$ equivalentes de catequina/mg no $\mathrm{AQ}$ e de $37,83 \mu \mathrm{g} / \mathrm{mL}$ equivalentes de catequina/mg no $\mathrm{ALC}$, respectivamente. $\mathrm{O} A \mathrm{AQ}$ apresentou uma concentração final de compostos fenólicos cerca de 11 vezes maior quando comparado ao ALC, demonstrando a maior eficiência da água na extração desses compostos.

A viabilidade das células secretoras de insulina foi avaliada pelo atividade mitocondrial (redução do MTT). As concentrações consideradas seguras (não tóxicas) para as células RINm5f foram aquelas nas quais foi evidenciada uma viabilidade igual ou superior a $90 \%$. O AQ não comprometeu a viabilidade celular na maioria das concentrações testadas. Apenas na maior concentração do extrato $(150 \mu \mathrm{g} / \mathrm{mL})$ a viabilidade celular foi inferior a $90 \%$. Já na presença do ALC, a viabilidade celular foi superior a $90 \%$ em todas as concentrações testadas. Nas concentrações mais baixas de ALC $(31,25 ; 62,5$ e $125 \mu \mathrm{g} / \mathrm{mL}$ ) a redução do MTT foi superior ao do grupo controle (controle $=100 \%$ de viabilidade) sendo este efeito um indicativo de aumento do metabolismo mitocondrial nessas concentrações (Tabela 1). 
Tabela 1. Citotoxicidade dos extratos aquoso (AQ) e alcoólico (ALC) de folhas de Eugenia uniflora L. em células RINm5f.

\begin{tabular}{llllll}
\hline Extrato $(\mu \mathrm{g} / \mathrm{mL})$ & AQ 12,5 & AQ 25 & AQ 50 & AQ 75 & AQ 150 \\
\hline & $103,5 \pm 1,42$ & $100,8 \pm 1,60$ & $98,43 \pm 1,09$ & $98,18 \pm 1,72$ & $75,94 \pm 0,59 * * *$ \\
\hline Extrato $(\mu \mathrm{g} / \mathrm{mL})$ & ALC 31,25 & ALC 62,5 & ALC 125 & ALC 250 & ALC 500 \\
\hline & $112,5 \pm 0,94^{* * *}$ & $110,6 \pm 1,71^{* * *}$ & $106,5 \pm 1,56^{* *}$ & $98,87 \pm 1,00$ & $94,22 \pm 0,64$ \\
\hline
\end{tabular}

Os resultados são expressos em porcentagem de viabilidade celular (controle $=100 \%$ de viabilidade) como média EEPM de 2 experimentos independentes $(n=8) .{ }^{* *} p<0,01 * * * p<0,001$

Nas células RINm5f submetidas ao estresse oxidativo induzido pelo peróxido de $\mathrm{H}_{2} \mathrm{O}_{2}$ (150 $\mu \mathrm{M})$ ocorreu uma redução da viabilidade celular em torno de $45 \%$ quando comparado ao grupo controle (ausência de $\mathrm{H}_{2} \mathrm{O}_{2}$ ). A redução da viabilidade celular induzida pelo $\mathrm{H}_{2} \mathrm{O}_{2}$, assim como o efeito das diferentes concentrações de AQ e ALC podem ser observados na Figura 1.

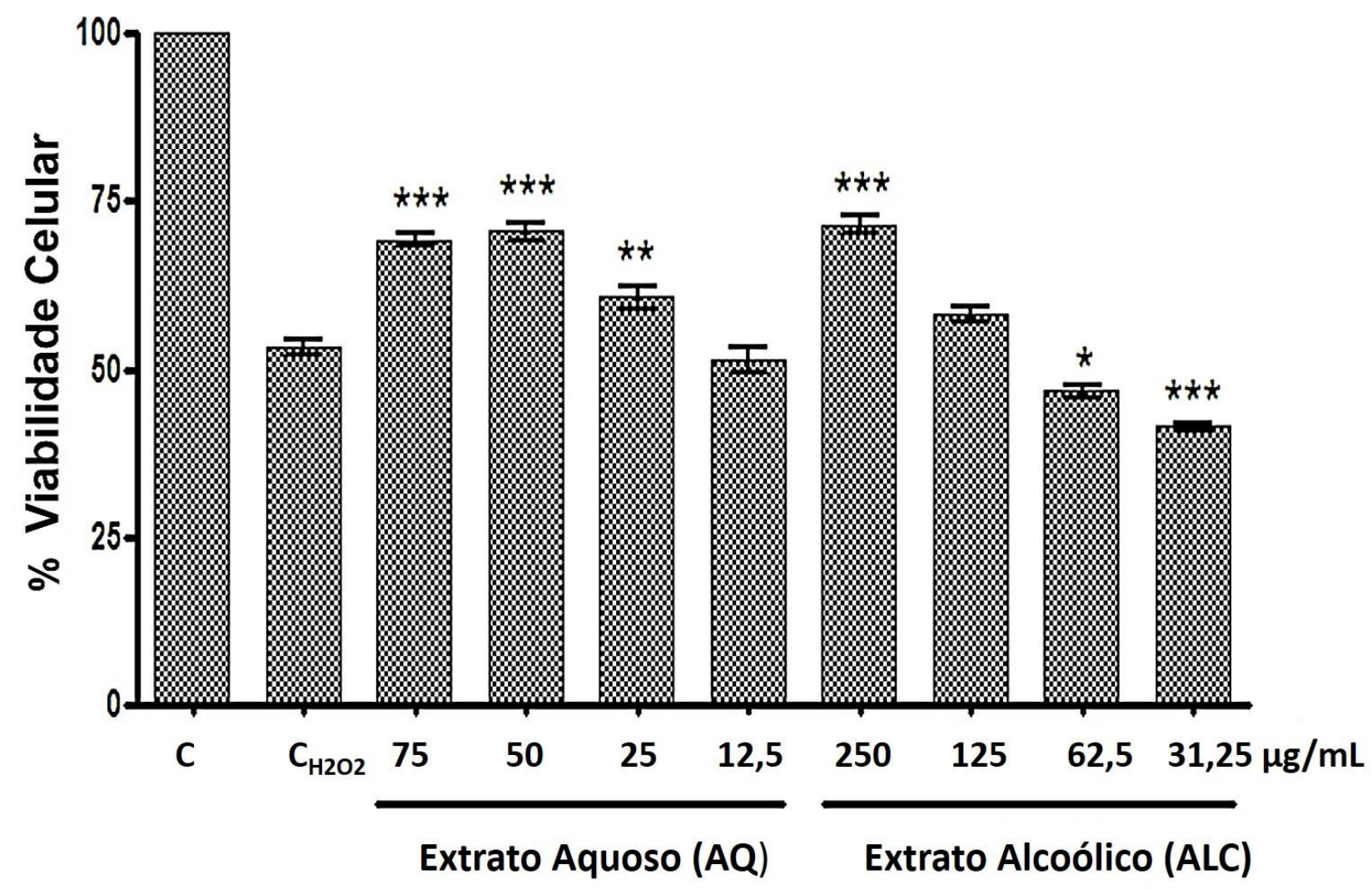

Figura 1. Atividade citoprotetora dos extratos aquoso (AQ) e alcoólico (ALC) das folhas de Eugenia uniflora $\mathrm{L}$ em células RINm5f após $24 \mathrm{~h}$ de exposição celular e estresse oxidativo induzido por $150 \mu \mathrm{M} \mathrm{H}_{2} \mathrm{O}_{2} / 2 \mathrm{~h}$. Os resultados são expressos como média \pm EPM. ${ }^{*} p<0,05,{ }^{*} p<0,01$ e ${ }^{* * *} p<0,001$ quando comparados ao grupo controle $\left(\mathrm{C}_{\mathrm{H} 2 \mathrm{O} 2}\right)$. Resultados representativos de 2 experimentos independentes $(n \geq 8)$.

A capacidade citoprotetora do $\mathrm{AQ}$ foi observada em praticamente todas as concentrações testadas $(75,50$ e $25 \mu \mathrm{g} / \mathrm{mL})$. Nessas concentrações a viabilidade celular foi, em média, $16,5 \%$ maior quando comparada com Colloq Vitae 2018 set-dez; 10(3): 42-53. DOI: 10.5747/cv.2018.v10.n3.v242 ISSN 1984-6436/C 2018 - Publicado pela Universidade do Oeste Paulista. Artigo Open Access sob uma licença CC BY-NC-ND (http://creativecommons.org/licenses/by-nc-nd/4.0/). o grupo controle $\mathrm{C}_{\mathrm{H} 2 \mathrm{O} 2}$. Já o $\mathrm{ALC}$ apresentou efeito citoprotetor apenas na concentração de 250 $\mu \mathrm{g} / \mathrm{mL}$, sendo verificado um aumento de $18 \%$ na viabilidade celular (comparado ao grupo controle $\mathrm{C}_{\mathrm{H} 2 \mathrm{O2}}$ ). Nas menores concentrações $(31,25$ e 62,5 
$\mu \mathrm{g} / \mathrm{mL}$ ) o ALC potencializou o efeito deletério do $\mathrm{H}_{2} \mathrm{O}_{2}$.

O efeito citoprotetor dos extratos também foi avaliado através da análise morfológica das células submetidas ao estresse oxidativo induzido por $\mathrm{H}_{2} \mathrm{O}_{2}$. $\mathrm{O}$ formato característico das células RINm5f é estrelado, com núcleo arredondado e o citoplasma rico em componentes aniônicos, o que confere a essas células uma intensa coloração por hematoxilina. Essas características podem ser evidenciadas na Figura $2 \mathrm{C}$ (células do grupo controle).

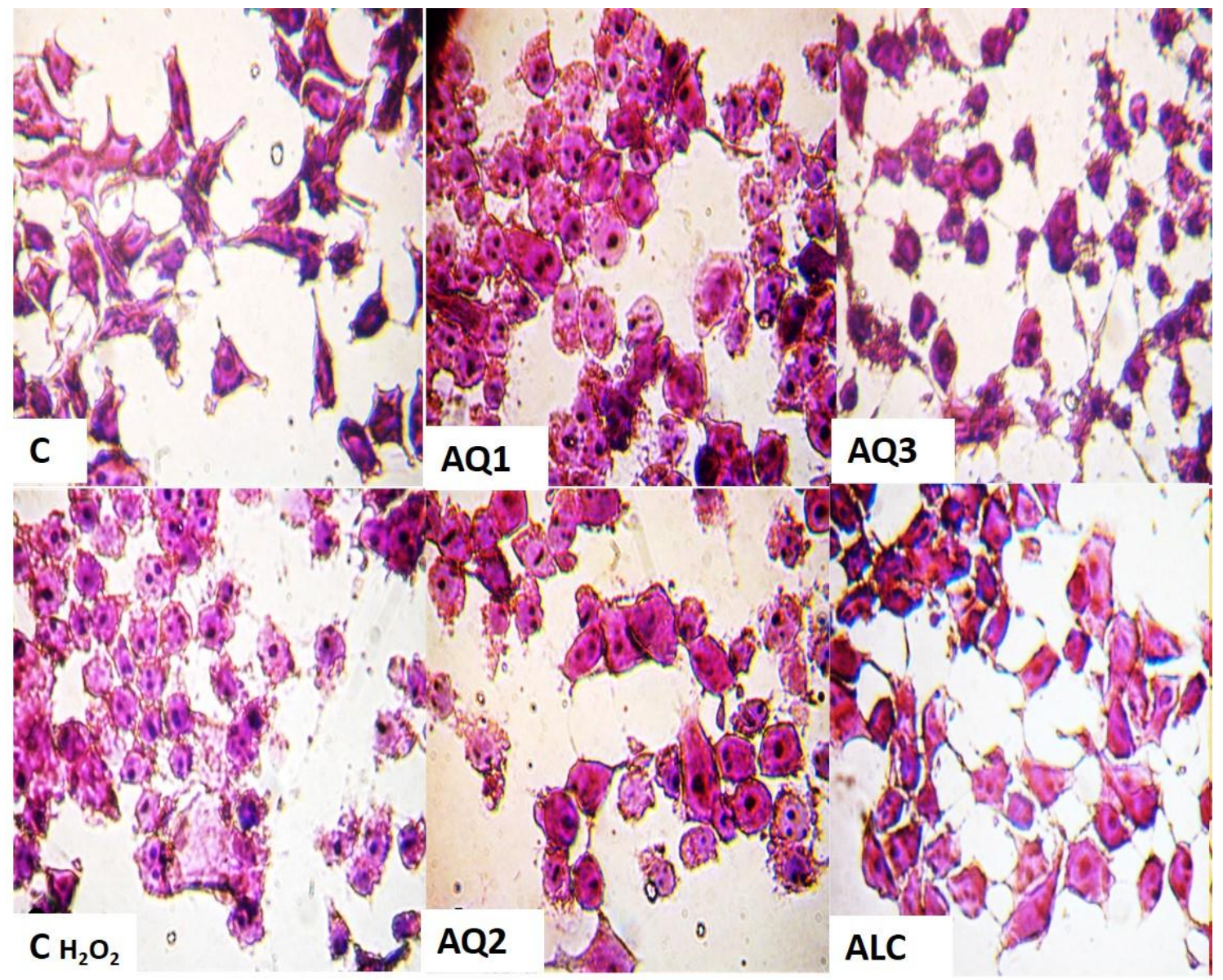

Figura 2. Morfologia das células RINm5f. Controle (C), controle com $\mathrm{H}_{2} \mathrm{O}_{2}: 150 \mu \mathrm{M} \mathrm{H} \mathrm{H}_{2} \mathrm{O}_{2} / 2 \mathrm{~h}\left(\mathrm{C}_{\mathrm{H} 2 \mathrm{O}}\right)$. Tratamentos com $24 \mathrm{~h}$ de exposição ao extrato aquoso: $A Q 1 ; A Q 2$ e $A Q 3-25 ; 50$ e $75 \mu \mathrm{g} / \mathrm{mL}$ de $A Q$, respectivamente. Tratamento com $24 \mathrm{~h}$ de exposição ao extrato alcoólico: ALC $250 \mu \mathrm{g} / \mathrm{mL}$ de extrato alcoólico. Resultados representativos de 2 experimentos independentes $(n=4)$. Coloração HE. Aumento 800x.

A adição da solução de $\mathrm{H}_{2} \mathrm{O}_{2}(150 \mu \mathrm{M})$ promoveu a perda de adesão intercelular com alteração no formato característico das células (Figura 2 - grupo $\mathrm{C}_{\mathrm{H} 2 \mathrm{O} 2}$ ). Na presença do $\mathrm{H}_{2} \mathrm{O}_{2}$, as células RINm5f adquiriram uma forma mais arredondada e a membrana plasmática de várias células apresentou aspecto irregular, com formação de pregas, citoplasma mais claro, redução da basofilia e núcleo mais evidente. Tanto o AQ $(75 \mu \mathrm{g} / \mathrm{mL})$ quanto o ALC $(250 \mu \mathrm{g} / \mathrm{mL})$ foram capazes de prevenir grande parte das alterações celulares induzidas pelo $\mathrm{H}_{2} \mathrm{O}_{2}$. Apesar da forma arredondada, as células tratadas com $\mathrm{AQ}$ e ALC nas concentrações protetoras tiveram algumas projeções citoplasmáticas preservadas. A basofilia citoplasmática apresentada por essas células foi semelhante ao do grupo controle e não apresentaram intensa formação de pregas na membrana plasmática (Figuras 2 - AQ3 e ALC).

Além da capacidade citoprotetora, também foi avaliado o efeito dos extratos na funcionalidade das células RINm5f (Figura 3). 


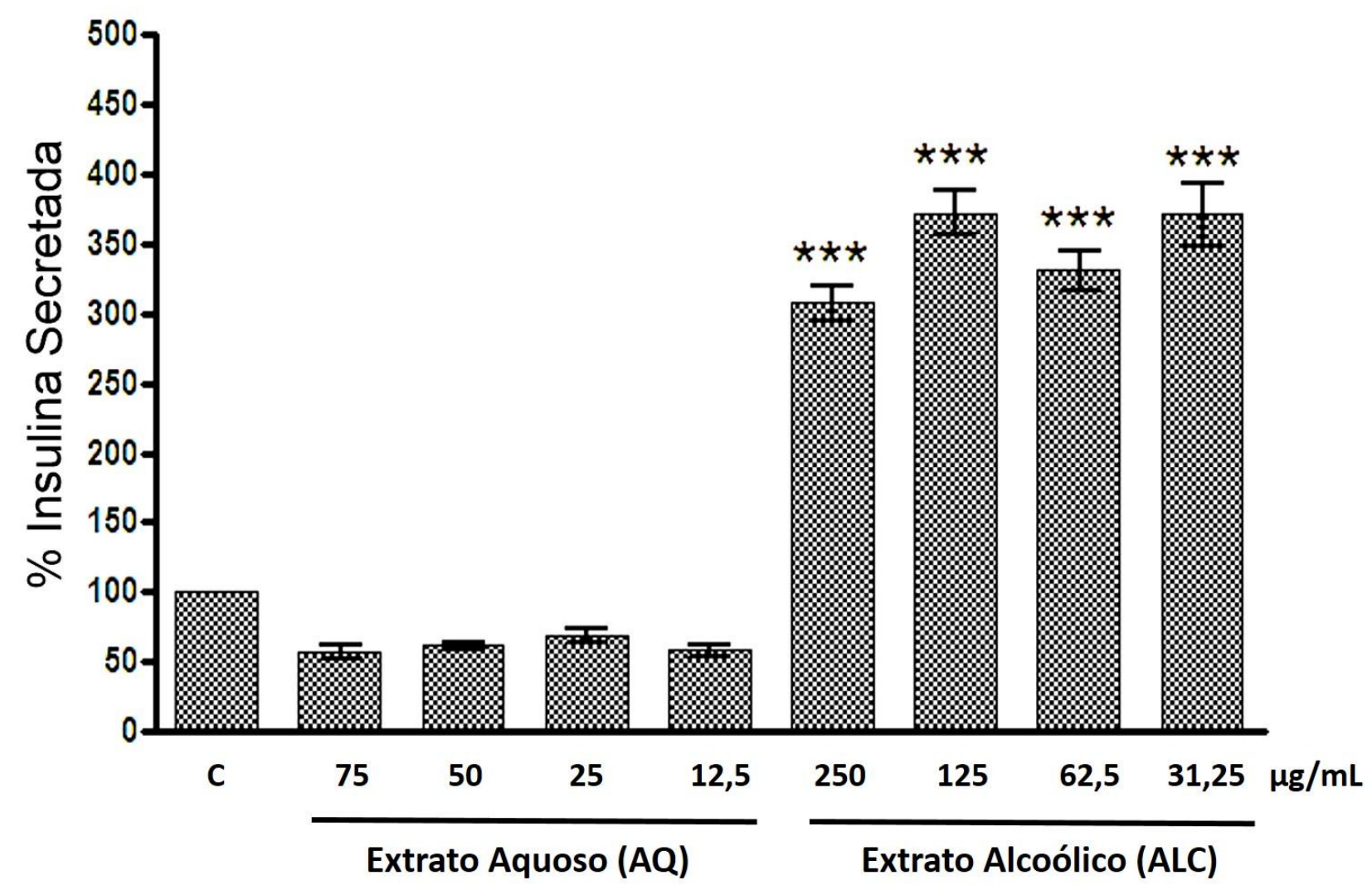

Figura 3. Secreção de insulina após tratamento das células RINm5f com extrato aquoso (AQ) e extrato alcoólico (ALC) de folhas de Eugenia uniflora $\mathrm{L}$. C=controle $(5,6 \mathrm{mM}$ de glicose e ausência de extrato). Os resultados são expressos como média \pm EPM. ${ }^{* * *} p<0,001$ quando comparados ao grupo controle (C). Resultados representativos de 2 experimentos independentes $(n \geq 10)$.

A secreção estática de insulina induzida por 5,6 mM de glicose foi analisada na ausência ou presença de diferentes concentrações de $A Q$ e ALC (grupo controle - 5,6 mM de glicose e ausência de extrato - $100 \%$ de secreção). O AQ não interferiu na secreção de insulina. Em contrapartida, o ALC, em todas as concentrações testadas, apresentou um significativo efeito insulinotrópico, promovendo um aumento de mais de 3 vezes na secreção basal de insulina comparado ao grupo controle (Controle $=100 \%$, extrato alcoólico: $31,25 \mu \mathrm{gg} / \mathrm{ml}=370 \% ; 62,5$ $\mu \mathrm{g} / \mathrm{ml}=330,5 \% ; 125 \mu \mathrm{g} / \mathrm{mL}=372 \%$ e $250 \mu \mathrm{g} / \mathrm{mL}=$ $307,5 \%)$.

\section{DISCUSSÃO}

No Brasil, as folhas de Eugenia uniflora L. são popularmente utilizadas, na forma de infusões ou extratos, no tratamento de diversas patologias, inclusive $\mathrm{o}$ diabetes mellitus. 0 potencial antidiabético da Eugenia uniflora L. foi atribuído, principalmente, a sua ação inibitória sobre enzimas intestinais, reduzindo o processo de digestão e absorção de glicose e a sua Colloq Vitae 2018 set-dez; 10(3): 42-53. DOI: 10.5747/cv.2018.v10.n3.v242 ISSN 1984-6436/@ 2018 - Publicado pela Universidade do Oeste Paulista. Artigo Open Access sob uma licença CC BY-NC-ND (http://creativecommons.org/licenses/by-nc-nd/4.0/). atividade anti-inflamatória sobre o pâncreas endócrino ${ }^{28,33}$. Apesar de vários estudos já terem avaliado a composição e a capacidade hipoglicemiante do extrato de folhas de Eugenia uniflora L., não há relatos do efeito direto desse extrato sobre a funcionalidade das células B pancreáticas.

As folhas de Eugenia uniflora L. são ricas em compostos fenólicos com comprovada atividade antioxidante, tais como quercetina, miricetina, rutina, ácido elágico e ácido gálico ${ }^{33,34}$. Muitos desses compostos, quando testados isoladamente, apresentaram significativa ação citoprotetora e hipoglicemiante. Neste trabalho foi avaliado o conteúdo total de compostos fenólicos presente em cada um dos extratos obtidos e foi verificado que a extração desses compostos em meio aquoso foi mais eficiente que em meio alcoólico.

Embora os compostos fenólicos tipicamente atuem como antioxidantes, com propriedades citoprotetoras, em determinadas condições eles podem também apresentar ação pró-oxidante. O comportamento dos flavonoides 
ou ácidos fenólicos como antioxidantes ou próoxidantes depende da natureza do estresse oxidativo, da susceptibilidade celular e das concentrações desses compostos. Um exemplo dessa variação de efeito é a genisteína, flavonoide derivado da soja, que modula a apoptose em células $B$ e em ilhotas pancreáticas de forma diferente de acordo com a sua concentração. Quando administrada em dose baixa $(25 \mu \mathrm{M})$ essa substância reduz a apoptose induzida por $\mathrm{NaF}$ (fluoreto de sódio) enquanto que em dose alta $(100 \mu \mathrm{M})$ potencializa o processo de morte celular ${ }^{35}$. Como o comportamento celular, frente aos diferentes extratos e as diferentes concentrações de um mesmo extrato vegetal pode variar muito, é essencial uma criteriosa avaliação da citotoxicidade de forma a garantir uma utilização racional e segura das plantas medicinais. Nesse trabalho foi verificado que $\mathrm{O} A Q$ apresentou efeito citotóxico (viabilidade menor que 90\%) sobre as células secretoras de insulina somente na concentração mais alta testada $(150 \mu \mathrm{g} / \mathrm{mL})$ enquanto doses mais baixas não interferiram na viabilidade ou proliferação celular, confirmando assim a segurança na utilização desse extrato. Já - ALC não reduziu a viabilidade celular em nenhuma das concentrações testadas, entretanto em três delas $(31,25,62,5$ e $125 \mu \mathrm{g} / \mathrm{mL})$ foi evidenciado um aumento na redução do MTT, sugestivo de aumento do metabolismo mitocondrial.

O ALC apresentou, em todas as concentrações testadas, um significativo efeito estimulatório sobre a secreção de insulina induzida pela glicose. O mecanismo através do qual esse extrato induz o aumento da secreção basal de insulina não foi investigado, entretanto uma hipótese é que este efeito possa ser, pelo menos em parte, resultante da estimulação do metabolismo mitocondrial (verificado no ensaio de redução do MTT) acompanhado de um provável aumento da relação ATP/ADP intracelular. Já o $A Q$ não apresentou efeito na secreção de insulina em nenhuma das concentrações testadas. Vários compostos isolados de extratos foliares já tiveram a sua ação insulinotrópica comprovada. 0 ácido gálico, por exemplo, um dos principais taninos presentes nas folhas de Eugenia uniflora L., estimula a expressão gênica e a secreção de insulina (efeito dose-dependente) em células $\mathrm{RINm}^{3} \mathrm{f}^{36}$. Possivelmente, a extração alcoólica realizada nesse estudo, apesar de não ter sido tão eficiente quanto a aquosa na extração de grandes quantidades de compostos fenólicos, possibilitou a extração de compostos com significativa ação insulinotrópica. Além disso, devido à baixa toxicidade, o ALC foi testado em concentrações mais elevadas quando comparado ao $A Q$, aumento assim a possibilidade de exposição das células RINm5f a maiores concentrações dos compostos insulinotrópicos.

Além do efeito direto sobre a secreção de insulina, também foi avaliada a capacidade citoprotetora dos extratos sobre as células RINm5f submetidas a estresse oxidativo. O AQ apresentou ação citoprotetora, prevenindo parcialmente a ação deletéria do $\mathrm{H}_{2} \mathrm{O}_{2}$, em praticamente todas as concentrações testadas. $\mathrm{O}$ $\mathrm{AQ}$ foi o que apresentou a maior concentração de compostos fenólicos e, sabidamente, a ação antioxidante desses compostos está amplamente relacionada com a proteção celular e prevenção do desenvolvimento de diversas patologias, entre elas o diabetes mellitus. A baixa atividade e expressão proteica de enzimas antioxidantes torna as células B pancreáticas muito susceptíveis aos danos celulares mediados por espécies altamente reativas ${ }^{16}$. Vários estudos demonstram a capacidade antioxidante e citoprotetora dos compostos fenólicos mais abundantes no extrato foliar de Eugenia uniflora sobre células pancreáticas. Coskun et al. $^{37}$, por exemplo, demonstraram o efeito citoprotetor da quercetina através da diminuição da peroxidação lipídica, inibição da geração de óxido nítrico e aumento da atividade de enzimas antioxidantes em ilhotas de ratos diabéticos. A elevada concentração de compostos fenólicos no $A Q$ possivelmente seja a responsável pela maior capacidade citoprotetora deste quando comparado ao ALC. Essa hipótese é reforçada pelo fato do ALC somente ter apresentado efeito citoprotetor semelhante ao do $A Q$ em alta concentração $(250 \mu \mathrm{g} / \mathrm{mL})$. Por outro lado, as concentrações mais baixas do ALC (31, 25 e 62,5 $\mu \mathrm{g} / \mathrm{mL}$ ) potencializaram o efeito deletério do $\mathrm{H}_{2} \mathrm{O}_{2}$. Essas coincidem com as concentrações de ALC em que foi evidenciado aumento do metabolismo mitocondrial (maior redução do MTT) nas células RINm5f. Uma hipótese é que esse aumento do metabolismo mitocondrial possa ter sido acompanhado de maior geração de EROs e consequente potencialização do estresse oxidativo induzido pelo $\mathrm{H}_{2} \mathrm{O}_{2}$. A baixa 
concentração de compostos fenólicos, acompanhada da reduzida atividade citoprotetora, é indicativo de que a atividade insulinotrópica do extrato ALC não é resultante de uma significativa atividade antioxidante.

As EROs, como superóxido, $\mathrm{H}_{2} \mathrm{O}_{2}$ e radical hidroxila podem comprometer a integridade e consequentemente a funcionalidade celular. As células RINm5f em cultura apresentam características epiteliais com grande adesão intercelular através de projeções citoplasmáticas mantidas por microfilamentos de actina. $\mathrm{O}$ estresse oxidativo induzido pelo $\mathrm{H}_{2} \mathrm{O}_{2}$ causou várias alterações morfológicas nas células RINm5f, como perda de adesão intercelular e alteração no formato celular (de estrelado para mais arredondado). Isto sugere provável alteração nos elementos estruturais (polímeros de actina) podendo levar a um aumento de permeabilidade e redução da seletividade da membrana celular ${ }^{38,39}$. Após incubação com o $\mathrm{H}_{2} \mathrm{O}_{2}$, a membrana plasmática de várias células apresentou aspecto irregular, com formação de pregas e citoplasma mais claro, possivelmente devido a desestruturação do retículo endoplasmático granular e consequente redução da basofilia. A provável perda do conteúdo citoplasmático, resultante da peroxidação lipídica e do aumento da permeabilidade da membrana, deixou o núcleo das células mais evidente. Além da peroxidação lipídica, o citoesqueleto é um dos primeiros alvos do estresse oxidativo ${ }^{40}$. Há uma gama crescente de evidências suportando a hipótese de que perturbações nas proteínas do citoesqueleto correspondem ao passo inicial dos danos induzidos por agentes oxidantes ${ }^{41}$. Efeito semelhante foi observado em células respiratórias epiteliais (Calu-3). Nessas células o estresse oxidativo induzido pelo $\mathrm{H}_{2} \mathrm{O}_{2}$ promoveu alterações no citoesqueleto e diminuição da seletividade de membrana ${ }^{42}$. A exposição das células RINm5f aos extratos aquoso $(75 \mu \mathrm{g} / \mathrm{mL})$ e alcoólico $(250 \mu \mathrm{g} / \mathrm{mL})$ preveniu muitas das alterações morfológicas induzidas pelo $\mathrm{H}_{2} \mathrm{O}_{2}$, comprovando a capacidade citoprotetora de ambos e sugerindo, neste caso, não uma ação direta dos compostos antioxidantes na neutralização das espécies reativas, mas a indução da expressão ou do aumento da atividade de mecanismos antioxidantes de defesa celular.

A partir dos resultados obtidos neste estudo foi possível concluir que os extratos aquoso e alcoólico testados apresentam atividade citoprotetora sobre as células secretoras de insulina e que o ALC possui uma significativa ação insulinotrópica. Esses resultados confirmam o potencial das folhas de Eugenia uniflora L. como coadjuvante tanto na prevenção quanto no tratamento do diabetes mellitus.

\section{AGRADECIMENTOS}

À Marlene dos Santos Rocha pelo auxílio na determinação da secreção de insulina por radioimunoensaio e ao Prof. Rui Curi (ICB-USP) pela doação das células RINm5f.

\section{CONFLITOS DE INTERESSE}

Os autores declaram não haver qualquer potencial conflito de interesse que possa interferir na imparcialidade deste trabalho científico.

\section{REFERÊNCIAS}

1. Galhiane MS, Rissato SR, Chierice GO, Almeida $M V$, Silva LC. Influence of different extraction methods on the yield and linalool content of the extracts of Eugenia uniflora L. Talanta. 2006;70(2):286-92.

DOI: https://dx.doi.org/10.1016/j.talanta.2006.02.040

2. Holetz FB, Pessini GL, Sanches NR, Cortez DAG, Nakamura CV, Dias FBP. Screening of some plants used in the Brazilian folk medicine for the treatment of infectious diseases. Mem Inst Oswaldo Cruz. 2002;97(7):1027-31. DOI: http://dx.doi.org/10.1590/S0074$\underline{02762002000700017}$

3. Kooti W, Farokhipour M, Asadzadeh Z, AshtaryLarky $D$, Asadi-Samani $M$. The role of medicinal plants in the treatment of diabetes: a systematic review. Electron Physician. 2016;8(1):183242. DOI: https://dx.doi.org/10.19082\%2F1832

4. Elder C. Ayurveda for diabetes mellitus: a review of the biomedical literature. Altern Ther Health Med. 2004;10:44-50.

5. Saxena A, Vikran NK. Role of selected Indian plants in management of type 2 diabetes: a review. J Altern Complem Med. 2004;10(2):36978.

DOI:

https://dx.doi.org/10.1089/10755530432306236 $\underline{5}$ 
6. Negri G. Diabetes melito: plantas e princípios ativos naturais hipoglicemiantes. Rev Bras Cienc Farm. 2005;41(2):122-42. DOI: https://dx.doi.org/10.1590/S1516$\underline{93322005000200002}$

7. Nyarko AK, Asare-Anane $\mathrm{H}$, Ofosuhene $\mathrm{M}$, ADDY ME. Extract of Ocimum canun lowers blood glucose and facilitates insulin release by isolated pancreatic beta-islet cells. Phytomedicine. 2002;9:346-50.

8. Yang K, Chan CB. Epicatechin potentiation of glucose-stimulated insulin secretion in INS-1 cells is not dependent on its antioxidant activity. Acts Pharmacol Sin. 2018;39(5):893-902. DOI: http://dx.doi.org/10.1038/aps.2017.174.

9. Grover JK, Vats V, Rathi SS, DAWAR R. Traditional Indian anti-diabetic plants Attenuate progression of renal damage in streptozotocin induced diabetic mice. J Ethnopharmacol. 2001;76:233-6.

DOI:

https://dx.doi.org/10.1016/S0378-

8741(01)00246-X

10. Rathi SS, Grover JK, Vats V. The effect of Momordica charantia and Mucuna pruriens in experimental diabetes and their effect on key metabolic enzymes involved in carbohydrate metabolism. Phytother Res. 2002;16:236-43. DOI: https://dx.doi.org/10.1002/ptr.842

11. Rajasekaran S, Sivagnam K, Subramanian S. Antioxidant Effect of Aloe vera gel extract in streptozotocin-induced diabetes in rats. Pharmacol Rep. 2005;57(1):90-6.

12. Fehresti Sani $M$, Montasser Kouhsari $S$, Moradabadi L. Effects of three medicinal plants extracts in experimental diabetes: Antioxidant enzymes activities and plasma lipids profiles in comparison with metformin. Iran J Pharm Res. 2012;11(3):897-903.

13. Broadhurst $\mathrm{CL}$, Polansky MM, Anderson R A. Insulin-like biological activity of culinary and medicinal plant aqueous extracts in vitro. J Agric Food Chem. 2000;48:849-52. DOI: http://dx.doi.org/10.1021/if9904517

14. Velázquez E, Tournier HA, Mordujovich de Buschiazzo P, Saavedra G, Schinella GR.
Antioxidant activity of Paraguayan plant extracts. Fitoterapia. 2003;74:91-7. DOI: https://dx.doi.org/10.1016/S0367326x(02)00293-9

15. Laybutt DR, Preston AM, Akerfeldt MC, Kench JG, Busch AK, Biankin AV et al. Endoplasmic reticulum stress contributes to beta cell apoptosis in type 2 diabetes. Diabetologia. 2007;50(4):752-63.

DOI: https://dx.doi.org/10.1007/s00125-006-0590-z

16. Lenzen S, Drinkgern J, Tiedge $M$. Low Antioxidant enzyme gene expression in pancreatic islets compared with various other mouse tissues. Free Radic Bio Med. 1996;20(3):463-466. DOI: https://dx.doi.org/10.1016/0891-5849(96)02051$\underline{5}$

17. Tiedge $\mathrm{M}$, Lortz $\mathrm{S}$, Drinkgern J, Lenzen $\mathrm{S}$. Relation between antioxidant enzyme gene expression and antioxidative defense status of insulin-producing cells. Diabetes. 1997;46(11):1733-42. DOI: https://dx.doi.org/10.2337/diab.46.11.1733

18. Newsholme $P$, Haber EP, Hirabara SM, Rebelato EL, Procopio J, Morgan D, OliveiraEmilio HC, Carpinelli AR, Curi R. Diabetes associated cell stress and dysfunction: role of mitochondrial and non-mitochondrial ROS production and activity. J Physio. 2007;583(1):924.

DOI: https://dx.doi.org/10.1113/iphysiol.2007.135871

19. Oliveira HR, Verlengia $R$, Carvalho $C R$, Britto LR, Curi R, Carpinelli AR. Pancreatic b-cells express phagocyte-like $\mathrm{NAD}(\mathrm{P}) \mathrm{H}$ oxidase. Diabetes. 2003;52(6):1457-63. DOI: https://dx.doi.org/10.2337/diabetes.52.6.1457

20. Cotelle N, Bernier JL, Catteau JP, Pommery J, Wallet JC, Gaydou EM. Antioxidant proprieties of hydroxy-flavones. Free Radic Bio Med. 1996;20(1):35-43. DOI: https://dx.doi.org/10.1016/0891-5849(95)02014$\underline{4}$

21. Okada Y, Kaneko M, Okajima H. Hydroxyl radical scavenging activity of naturally occurring furan fatty acids. Bio Pharm Bull. 
1996;19(12):1607-10.

DOI: https://dx.doi.org/10.1248/bpb.19.1607

22. Reynertson KA, Basile MJ, Kennelly EJ. Antioxidant potential of seven myrtaceous fruits. Ethnobotany Res Appl. 2005;3:25-35. DOI: https://dx.doi.org/10.17348/era.3.0.25-36

23. Coentrão PAM. Avaliação de três técnicas de isolamento de polifenóis: aplicação em amostras de chocolate meio amargo. [Dissertação]. Niterói: Universidade Federal Fluminense, 2005.

24. Knekt $P$, Kumpulainen J, Järvinen $R$, Rissanen $H$, Heliövaara $M$, Reunanen A et al. Flavonoid intake and risk of chronic diseases. Am J Clin Nutr. 2002;76(3):560-8. DOI: https://dx.doi.org/10.1093/ajen/76.3.560

25. Song Y, Manson JE, Buring JE, Sesso HD, Liu S. Associations of dietary flavonoids with risk of type 2 diabetes, and markers of insulin resistance and systemic inflammation in women: A prospective study and cross-sectional analysis. J Am Coll Nutr. 2005;24(5):376-84. DOI: https://dx.doi.org/10.1080/07315724.2005.1071 $\underline{9488}$

26. Rattmann DY, Souza LM, Paiva MMS, Dartora N, Sassaki GL, Goin PAJ, lacomini M. Analysis of flavonoids from Eugenia uniflora leaves and its protective effect against murine sepsis. ECAM. 2012;1-9.

DOI: http://dx.doi.org/10.1155/2012/623940

27. Bezerra ICF, Ramos RTM, Ferreira MRA, Soares LAL. Chromatographic profiles of extractives from leaves of Eugenia uniflora. Rev Bras Farmacogn. 2018;28(1):92-101. DOI: http://dx.doi.org/10.1016/j.bjp.2017.11.002.

28. Momose Y. Pentahydoryndolizidine and aglucosidase inhibitors containing products of Eugenia uniflora. Jpn. Kokai Tokkyo Koho, 2000;72:770, Apud: Chem Abstr. 132, abstr. n. 203147, v. 2000.

29. Moyer RA, Hummer KE, Finn CE, Frei B, Wrolstad RE. Anthocyanins, Phenolics, and Antioxidant Capacity in Diverse Small Fruits: Vaccinium, Rubus, and Ribes. J Agric Food Chem. 2002;50(3):519-25. DOI: http://dx.doi.org/10.1021/jf011062r
30. Mosmann T. Rapid colorimetric assay for cellular growth and survival: application to proliferation and cytotoxicity assays. J Immunol Methods, 1983;65(1-2):55-63. DOI: https://dx.doi.org/10.1016/0022-1759(83)90303$\underline{4}$

31. Pupo AA, Marreiro D. Dosage of insulin levels using radioimmunoassay with double antibodies. AMB Rev Assoc Med Bras. 1970;16(5): 153-6.

32. Morgan C R, Lazarow A. Immunoassay of insulin: two antibodies system: plasma insulin levels of normal, subdiabetic and diabetic rats. Diabetes. 1963;12(2):115-21. DOI: https://dx.doi.org/10.2337/diab.12.2.115

33. Schumacher NS, Colomeu TC, de Figueiredo D, Carvalho V de C, Cazarin CB, Prado MA, et al. Identification and Antioxidant Activity of the extracts of Eugenia uniflora Leaves. Characterization of the anti-Inflammatory properties of aqueous extract on diabetes expression in an experimental model of spontaneous type 1 diabetes (NOD Mice). Antioxidants. 2015;4(4):662-80. DOI: https://dx.doi.org/10.3390/antiox4040662

34. Falcão $T R$, de Araújo $A A$, Soares $L A L$, de Moraes Ramos RT, Bezerra ICF, Ferreira MRA et al. Crude extract and fractions from Eugenia uniflora Linn leaves showed anti-inflammatory, antioxidant, and antibacterial activities. BMC Complement Altern Med. 2018;18(1):84. DOI: https://dx.doi.org/10.1186/s12906-018-2144-6

35. Elliott J, Scarpello JH, Morgan NG. Differential effects of genistein on apoptosis induced by fluoride and pertussis toxin in human and rat pancreatic islets and RINm5F cells. J Endocrinol. 2002;172(1):137-43. DOI: http://dx.doi.org/10.1677/joe.0.1720137

36. Sameermahmood Z, Raji L, Saravanan $T$, Vaidya A, Mohan $V$, Balasubramanyam $M$. Gallic acid protects RINm5F beta-cells from glucolipotoxicity by its antiapoptotic and insulinsecretagogue actions. Phytother Res. 2010;S1:8394. DOI: https://dx.doi.org/10.1002/ptr.2926

37. Coskun O, Kanter M, Korkmaz A, Oter S. Quercetin, a flavonoid antioxidant, prevents and 
protects streptozotocin-induced oxidative stress and beta-cell damage in rat pancreas. Pharmacol Res. 2005;51(2):117-23. DOI: https://dx.doi.org/10.1016/j.phrs.2004.06.002

38. Pérez $M$, Barber A, Ponz F. Modulation of intestinal paracellular permeability by intracellular mediators and cytoskeleton. Can J Physiol Pharmacol. 1997;75(4):287-92. DOI: https://dx.doi.org/10.1139/y97-059

39. Stevenson BR, Begg DA. Concentrationdependent effects of cytochalasin $D$ on tight junctions and actin filaments in MDCK epithelial cells. J Cell Sci. 1994;107(Pt3):367-75.

40. Dalle-Donne I, Rossi R, Milzani A, Di Simplicio $P$, Colombo R. The actin cytoskeleton response to oxidants: from small heat shock protein phosphorylation to changes in the redox state of actin itself. Free Radic Biol Med 2001;31(12):1624-32. DOI: https://dx.doi.org/10.1016/S0891$\underline{\text { 5849(01)00749-3 }}$

41. Zhu D, Tan KS, Zhang $X$, Sun AY, Sun GY, Lee JC. Hydrogen peroxide alters membrane and cytoskeleton properties and increases intercellular connections in astrocytes. J Cell Sci. 2005;118(16):3695-703.

DOI: https://dx.doi.org/10.1242/jcs.02507

42. Boardman KC, Aryal AM, Miller WM, Waters $\mathrm{CM}$. Actin re-distribution in response to hydrogen peroxide in airway epithelial cells. J Cell Physiol. 2004;199(1):57-66.

DOI: https://dx.doi.org/10.1002/jcp.10451

Recebido para publicação em 23/12/2018

Revisado em 25/02/2019

Aceito em 14/03/2019 